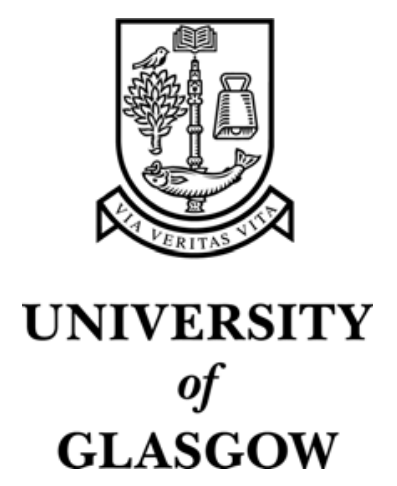

Johnston, Sean F. (2003) Reconstructing the history of holography. In, Practical Holography XVII, 21-23 January 2003 Proceedings of the SPIE Vol 5005, pages pp. 455-464, Santa Clara CA.

http://eprints.gla.ac.uk/archive/2897/ 


\title{
Reconstructing the History of Holography
}

\author{
Sean F. Johnston*, University of Glasgow Crichton Campus, Dumfries, Scotland, DG1 4ZL
}

\begin{abstract}
This paper discusses large-scale but gradual changes in the subject of holography that have only recently become readily observable. Presenting an analysis of publications in holography over the past half century, the paper illustrates and discusses the evolving shape of the subject. Over 40,000 international information sources have been recorded, including some 20,000 papers, 10,000 conference presentations, 7,000 patents, 1,000 books, nearly as many theses and at least 500 exhibitions. This statistical and sociological approach is combined with the identification of specific factors - notably the role of individuals, conferences, proof-of-concept demonstrations and exhibitions - to suggest that the development of holography has been unusually contingent on a variety of intellectual and social influences. The paper situates these observations about holography and holographers in the context of a wider discussion about the styles, purposes and difficulties of historical writing on technological subjects. It further suggests that this ongoing process of both recording and reconstructing technological history can be aided by identification of sources sometimes overlooked or undervalued by practitioners: unpublished archival materials such as private file collections; business records; accounts of unsuccessful activities; and, by no means least, anecdotal accounts inter-linked between participants.
\end{abstract}

Keywords: Holography; holographer; history; sociology; technology; technological evolution; profession; discipline.

\section{INTRODUCTION - WHY A HISTORY OF HOLOGRAPHY, AND WHY NOW?}

Holography is now slightly over half a century old, if we mark its birth from the first work of Dennis Gabor, or over four decades old as a laser-based technology. During this time, it has engendered awe in new viewers, provoked repeated waves of commercial excitement from entrepreneurs, and generated enduring satisfaction and frustration among holographers - the scientists, engineers, artists and enthusiasts who practice it.

There are several reasons for now attempting to track, record and analyze the many activities that occurred during this time. One is that anniversaries have traditionally been appealing points at which to look back and survey progress. A half-century represents such an anniversary, and in human terms represents either the maturity of middle age or the span of a full career. A second reason for writing a history of holography could be because holography has entered a different phase of its evolution. For example, one application (security embossed holograms) today dominates the market while other longer-lived activities, such as creative holography and non-destructive testing, are now less active than formerly. These changes have led to an altered profile for practitioners motivated by new economic and technical concerns, perhaps beginning a new chapter of the subject. Yet another reason for a history might be as a justification: to communicate a sense of purpose and community regarding activities in holography; to explain its achievements and personalities to those who follow, and to illustrate a trajectory that might not be obvious to non-specialists. And perhaps the most obvious reason for writing a history now is that the first generation of practitioners will not be available indefinitely to provide first-hand accounts.

As an historian of science and technology, my own motivations for studying the history of holography include some of these reasons but extend beyond them, and seek to understand the subject in the wider context of its times and its context in the intellectual currents of those times. There are several aspects to this: first, to record accurate factual details and relationships, i.e. what is commonly understood as the nuts and bolts of history writing; second, to explain the course followed by this specialty by relating it to wider scientific and social events; and third, to use this case as a means of extending broad understandings of how late twentieth century technological subjects have evolved. History of science and technology can be a balanced way of recording achievements, personal contributions and experiences. It can also be a means of understanding general processes of development. There are thus historical, sociological, economic and policy motivations for such research.

*s.johnston@crichton.gla.ac.uk; phone +44 (1387) 702038; fax +44 (1387) 702005; www.cc.gla.ac.uk 


\section{PROBLEMS OF HISTORY WRITING}

The writing of history can never be an entirely objective process. What we choose to record, and how we record it, is determined by our own knowledge, expectations and interpretations. As a contributor to this meeting, I could be labeled in some respects as a relative outsider. I have published a single paper on holography, although as an optical physicist I have worked for a number of years in closely related areas of physical optics. On the other hand, a professional separation from the subject is not necessarily a disadvantage. Avoiding subjectivity in history writing can be peculiarly difficult for active participants. Those involved in developing or extending a field - except perhaps the practitioners who are the most experienced and long-lived - can struggle to provide an objective and wide-ranging account. Only a small proportion of workers can claim the requisite background. ${ }^{1-3}$ To counteract this problem, history tends to be written many years after the fact, and often by those who have had little direct involvement with the subject. From a distance, events often appear more coherent because we gain a sense of the large-scale influences that may not have been obvious at the time. To cite an example, the rapid growth in scientific research through the 1950s and 60s was interpreted by many contemporary commentators as entirely typical of a modern technological society, but we recognize today that the Cold War era introduced a very unusual scale of science funding by military sponsors, with significant knock-on effects. Another recent example is alternate accounts of the history of the laser. ${ }^{4-6}$ So distance from the events can provide an alternate perspective. On the other hand, this distance can limit us to a myopic view. It can obscure the complexity of detail that influenced the trajectory of development. Writing about the history of technology is therefore fraught with difficulty. Historians strive to develop an objective view and to paint the 'big picture'. In modern studies of science and technology, however, there is a need to understand the dynamics of new subjects, new disciplines, and new professions. We do not as often allow ourselves the luxury of a leisurely view of the past. History is studied for specific purposes: to make policy decisions, produce or extend inventions, or exploit a technology for profit. There is therefore an essential tension in the history of science and technology: between technical accuracy on the one hand and faithfulness to the spirit of an age on the other; or between detail and widespread effects; or between practitioners' history (formerly referred to as 'internal' history) and wider social and economic accounts (sometimes called 'external' histories).

One conclusion of this introductory discussion is that histories are written for different audiences. A history written for practitioners of holography may be very unsatisfying for the general public or for academic historians, and vice versa. But it is also true that history writing is a product of a time and a place. It also follows that there are many ways of writing unsatisfactory history. For example, if we rely solely on the memories of survivors - those individuals and firms that had a long period of activity in holography - we are likely to produce a biased history. It is necessary to collate not only successes, but failures, too - and there have been many commercial failures, and more than a few technical deadends, in the field of holography. This is an entirely typical but frequently under-represented situation in the history of sciences and technologies. Similarly, if we rely on published records such as papers and conference proceedings, we miss the human scale, the personality conflicts and inspirational practitioners. The aim, therefore, must be to write history that samples all these scales, and transcends the reader's time and place, retaining its sense of accuracy and perceptiveness for succeeding generations.

Some participants at this meeting will be able to provide detailed accounts of episodes in the history of holography. I shall not attempt to relate anecdotes or specific incidents, because that is best done by participants themselves - the socalled historical actors (you know who you are!). Instead, I will begin at the other end of the spectrum, discussing some rather large-scale and gradual changes in the subject of holography that have only recently become readily observable. This combines a statistical approach with a sociological interpretation. I will describe the large, slow changes that occurred over half a century. This can be a useful approach because not all trends were obvious as they occurred. It is one reason that historians often prefer to wait to get a sense of the deeper changes in the subject, and it can lead them, eventually, to different explanations for why various events occurred the way they did.

\section{STATISTICS OF HOLOGRAPHY}

The foregoing is a mere preamble - an introduction and motivation for the writing of history.

Over its first half century, holography has been influential at a wide range of scales. Numbers can put its impact into perspective. The subject has attracted thousands of researchers, designers and other creators, and hundreds of discrete 
applications. Some 20,000 papers have been published, and over 10,000 conference presentations presented. Some 7,000 patents have been granted, a thousand books published, nearly as many theses defended, and at least 500 exhibitions staged. These could be called 'public statistics'. But there are also private statistics. Perhaps market-tracking organizations like Reconnaissance International can suggest how much money has been generated or lost by holographic firms or provided by grant agencies, corporations and other sponsors. This is one semi-public statistic that is still difficult to discern.

This scale is considerably greater than some other late $20^{\text {th }}$ century technologies and nascent sciences. So large, in fact, that the scale itself allows certain trends to be tracked. One relevant approach is 'bibliometry' - the measuring of publications.

Databases of publications, maintained by academic libraries, institutions and private indexing firms, suggest the rate of activity in the subject of holography. Figure 1 plots the annual rate of publications of several kinds: books, dissertations, conference presentations, exhibitions, papers and patents. No single source is complete, because papers on holography have been distributed among a wide variety of journals, magazines, publishers, organizers and countries. And some forms of publication, such as art exhibitions, are poorly represented in such databases, being listed, if at all, in the form of exhibition catalogues. Even patents can be awkward to quantify, because they may be filed in more than one country.

This kind of analysis can be skewed inadvertently in other ways. A major contribution to inaccuracy is the fact that much research is unpublished. For example, the side-looking radar research that led to holography studies by Leith and Upatnieks was supported by the American military and is still confidential, in parts. The same is true of some of the expertise in Head Up Displays (HUDs) and Holographic Optical Elements (HOEs). Even more commonly, commercial research is often unpublished to ensure a business advantage.

Even with these potential drawbacks, the attempt to quantify publications in holography can still reveal useful information. It is apparent, for example, that the venue of publication shifted with time. Books (Fig 1A) appeared at a near-constant rate 1970-1990, but declined thereafter. The completion of theses (Fig 1B) peaked in the early 1970s, during the first pulse of interest when research money was relatively plentiful, and again in the early 1990s, when a wider range of applications were identified and investigated. Perhaps surprisingly, the heyday of conference publications (Fig 1C) was between the mid 1970s and early 1980s, despite the proliferation of regular conferences under the auspices of the SPIE and IS\&T from the 1980s. Holography exhibitions (Fig 1D), both artistic and for wider publics, were an important setting for information transfer during the 1980s, but have declined significantly since then. From the handful of yearly publications from 1947, papers in scientific journals (Fig 1E) exploded in 1965; indeed, the earlier publications by Gabor, El-Sum and others are scarcely visible at this graphical scale. ${ }^{7-13}$ Papers peaked in 1971, about the time that some highly visible players such McDonnell Douglas were actively promoting holographic technology for advertising displays, pulsed-laser portraiture and non-destructive testing. McDonnell Douglas closed its production facility in 1973, reflecting a wider loss of confidence by American funders of holography. Scientific and engineering papers gradually rose to a higher maximum in the mid 1990s, but since that time they have fallen two-fold. The granting of patents (Fig 1F) also evinced a peak in the early 1970s and then, from the early 1980s, has risen steadily.

The journals of publication have also shifted as holography has been redefined as a subject and nascent specialty. The first post-war publications were in journals of general science or physics (e.g. Nature, Journal of Applied Physics, Applied Physics Letters, Oyo Buturi). During the holography boom of the 1960s, publications appeared as frequently in these as in a wide range of journals of modern optics (e.g. Applied Optics, Journal of the Optical Society of America, Optica Acta, Optics \& Spectroscopy, Optics Communications, Optik) and electronics (e.g. Bell Systems Journal, Proceedings of the IEEE, Radiotechnika i Elektronika). The early Soviet contributions to the subject were less accessible than western publications, and were undervalued both at home and abroad. ${ }^{14-17}$ By the early 1970s the profession of optical engineering, considerably boosted by military funding, usurped these prior domains of publication, and in America Optical Engineering and Applied Optics became increasingly important publications for papers concerning holography. During the late 1970s and 1980s, a number of limited circulation or short-lived magazines and newsletters for self-styled holographers appeared (Holosphere, L.A.S.E.R. News, Wavefront, Holographics International, Creative Holography Index and others). These opened a new informal and unrefereed communication channel for practitioners. This unceremonious medium reflected the changing constituency of holographers themselves: by this period, artists and entrepreneurs were becoming a vocal subculture in the field. ${ }^{18}$ Most of these grassroots publications had ceased publication by the mid 1990s, with holography business newsletters (e.g. Holography News) 
servicing the new economic concerns of commercial embossed holography. Thus, the latency of some publication venues reflects a changing social and professional profile for holography.

The overall rate of publication via all these sources was rather uniform. Publications as a whole showed a dramatic rise from 1965 to 1972, a near static rate for a further decade, and then a rise to the early 1990s and a subsequent fall-back (Fig 1G). If the unpublished military and commercial activities could be represented on this graph, the rate of work through the 1960s-80s would be somewhat higher.

\section{CONTINGENCY OF DEVELOPMENT}

The results shown here are merely a beginning - and a rather large-scale, impersonal and unsatisfying suggestion of the evolution of the subject at that. Clearly these international trends could be analyzed further to show national nuances, and could be further subdivided along professional or disciplinary lines. But beyond bibliometry, other approaches and further information are needed to write an accurate and meaningful history.

One problem with presenting information of this sort is that it suggests a certain inevitability. The implicit idea is that technological progress rolls forward almost uncontrollably, and that it entrains consequences that themselves may be largely unavoidable. The writings of Thomas Parke Hughes exploring technological momentum have been influential in countering these simplistic assumptions in the history of technology. ${ }^{19-21}$ As holographers fully appreciate, the subject has been shaped not only by a certain technological momentum but also by enthusiastic individuals and by perceived applications and market niches. The directions in which it has evolved have been contingent on rapidly changing circumstances, and influenced by disparate factors. Four examples can illustrate this.

First, an important role has been played individuals who have become, in effect, spokespersons and eventually elder statesmen of the subject. Professor Emmett Leith has, from the very first months of laser holography, served as popularizer, translator and prognosticator of the new field with his then-associate Juris Upatnieks. Their newspaper interviews, articles for Scientific American, and forecasts in trade journals brought an awareness of holography to the general public and technologists as well as other scientists. ${ }^{22-28}$ Popularization of this sort created and sustained a level of interest that led to public demonstrations and high school experiments as well as successful grant proposals for a quickly growing band of practitioners. But Dennis Gabor, Emmett Leith, Yuri Denisyuk, Stephen Benton and others have also provided a restraining and stabilizing effect on the subject by their continuity in the field: restraining the impulse to exaggerate, over-promise and distort public expectations. Thus certain individuals have had an influence in shaping the forecasts about holography and, given the importance of technical predictions for research directions, venture capitalists and commercial start-ups, they have to some extent directed the evolution of holography itself. ${ }^{29-34}$

A second example of the contingency of this field concerns the role of meetings. In nascent technical fields that have not become professionalised, meetings can be a significant means of transferring information and building a sense of community (note from Fig 1C the early importance of conference publications in holography). The very successful Symposium on Display Holography organized by Professor Tung Jeong at Lake Forest College, Illinois in 1982 is an example of this. Repeated every three years, these symposia played a seminal role in bringing together not only scientists and technologists, but artists, entrepreneurs and enthusiasts, too. The Lake Forest symposia helped to foster and promote new sub-cultures of holographers. SPIE itself has fostered these communities of practitioners by publishing the proceedings in later years. Each conference series has drawn a different mixture of individuals, disciplines and market niches. The first conferences focused on engineering applications, and attracted engineers and scientists. ${ }^{35-38}$ The SPIE itself has organized some eighty conferences on holography since 1968. The first Practical Holography conference was held in 1986 and has been an annual event ever since. It drew a relatively high proportion of entrepreneurs and technologists in the large firms. The Lake Forest Symposia arguably had an even wider mix of backgrounds and interests. It is to be hoped that something like the Symposia of Display Holography can be continued, because the blend of participants and applications was unusually productive for the subject and its nascent communities.

These conferences are particularly important in bringing a sense of collective identity to a subject that has not had a dedicated journal. I have already mentioned how the publishing channel for holography has moved over the years. The shift in disciplines is illustrated in Figure 2. Early papers on holography appeared in journals of general science or physics. During the late 1950s, more were published in optical journals and some electronics journals. After the first 
laser holograms, a glut of papers appeared in journals covering the disciplinary spectrum: from general science to optics, electronics and engineering. From the mid 1960s to the end of the century, the proportion of engineering papers has risen gradually, reflecting the growing range of applications. This enduring division of the field between different disciplines (optical physics, electrical engineering, optical engineering and non-destructive testing) is unusual, and is one illustration of how the subject has resisted professionalisation. Besides incomplete disciplinization and professionalisation, the occupation of holography has also had a difficult time becoming established. The 'holographer' was largely a creation of the late 1970s and 1980s. Holographers proclaimed themselves as such in San Francisco, at Lake Forest and in New York, as well as in St. Petersburg, London, Paris and Munich. The locus for these early holographers, and the development of their sense of identity, was at schools of holography, which provided short courses from the early 1970s and trained the first generation of artists (The San Francisco School of Holography operated between 1971-1974 and again from 1977; Lake Forest College, Illinois, began week-long classes in 1972; the New York School of Holography was established in 1973; many more courses began at further education colleges and art schools around the world from the late 1970s). Here, too, specialized conferences have promoted the occupation and its multiple expressions in art, design engineering, advertising, mechanical testing and so on. Periodicals such as Holosphere and organizations such as the New York Museum of Holography $(\mathrm{MoH})$ were important in stabilizing practice and expanding these communities (Holosphere was published 1972-1990, and by the MoH from 1976).

A third example of the contingency of this young subject is the dramatic repercussions from demonstration technology, i.e. inspirational holograms. The consequences of showing Leith's and Upatniek's train hologram at the 1964 meeting of the Optical Society of America are well known. ${ }^{39}$ Many physicists left the meeting inspired to recreate the phenomenon. Another case is the so-called 'multiplex' or integral hologram developed and popularized by Lloyd Cross from the early 1970s, which had a strong popular impact. The Multiplex Corporation in San Francisco sold many examples of these cylindrical holographic stereograms to museums, shops and individuals. ${ }^{40}$ Because the Cross hologram was also a rainbow hologram, it could be viewed in white light. ${ }^{41}$ And since its component strip holograms were synthesized from individual frames of movie film, it reconstructed a few seconds of three-dimensional motion when it rotated. These two attributes - white light reconstruction and animation, combined with their ubiquitous display in science centers and shops - captured the imagination of the public and writers. ${ }^{42,43}$ Films from the mid 1970s began to represent the hologram as a synthetic three-dimensional projection, an attribute neither claimed nor predicted by contemporary holographers. These included the films Logan's Run (1976), Star Wars (1977), and the television series Red Dwarf (pilot written in 1983, series broadcast in Britain 1988-1994) and the later Star Trek television series The Next Generation (broadcast 1987-1994) with its 'holodeck', or holographic visualization room, Deep Space Nine (19931999) with 'holosuites', and Voyager (1995-2001) with its 'Emergency Medical Hologram', or virtual doctor. This bifurcation of technologists' and science fiction writers' perceptions began during the 1970s. Popular engagement with holography mutated further during the early 1980s when, owing largely to the writings of psycho-physiologist Karl Pribram, physicist David Bohm and popularizer Ken Wilber, holograms were increasingly touted as analogies or even models of human consciousness and the physical universe. ${ }^{44-48}$

My fourth example of the sensitivity of this subject to infrequent events is the dramatic effect played by public exhibitions of holography. In London, for example, the Light Fantastic exhibitions of 1977 and 1978 reputedly attracted a quarter-million attendees and spawned small sales outlets and shops during the early 1980s, the encouragement of a cottage industry producing display holograms, and paid-entry venues such as the Trocadero gallery in London. Holografi - Det Nya Mediet (Stockholm, Sweden, 1976) and Through the Looking Glass (originating at the Museum of Holography in New York in 1978 and subsequently traveling around the US), were similarly influential presentations of this period. Such exhibitions of the late 1970s were also the first public displays in the west of Soviet holograms, which had an impact on emulsion research there. ${ }^{49}$ Other influential exhibitions of this era were Space-Light (Sydney, Australia, 1982), Light Dimensions (Bath, UK, 1983) and Images in Time and Space (Montreal, 1987, and a traveling show thereafter). Each of these drew tens of thousands of visitors.

These four examples of the role of individuals, conferences, proof-of-concept demonstrations and exhibitions in influencing the subject suggest that the evolution of holography could have been otherwise. Without its proselytizers, participants and promoters the course of this subject would have been differently funded, differently timed or differently perceived. On the other hand, some aspects of the history of holography seem to have been played out previously for other technologies in other circumstances. Take, for example, the popular interest in holograms as three-dimensional images. The popularization of holograms, which began as scientific curiosities, evolved into art objects and degenerated into decorations on children's toys, has close parallels in the history of stereoscopic and lenticular photographs. 
Previous stereoscopic media included stereo Daguerreotypes (c1851), stereoscopes (1880s-), the View-Master (1938-), Stereo-Realist and other stereo cameras (c1948-c1956), 3-D movies (1952-c1956) and the Xograph (lenticular-screen images, c1952-). Most of these evinced a trajectory of popular appeal followed by declining interest, and a transformation for the novelty or children's markets. ${ }^{50,51}$ The popular engagement with holography is evidently intertwined with cumulative experiences of these other media.

\section{A HISTORY IN PROGRESS}

Given this complex subject so sensitive to particular historical trigger points and interlinked with wider culture, how can a representative and meaningful history be written?

For any historian, the aim is to bring to life a realistic representation of the past. To use the analogy of holography itself, the goal is to reconstruct a rounded, animated and colorful image. The public statistics presented above suggest large scale trends. But 'private statistics' - personal accounts - are also needed. The image cannot be based solidly on anecdotes or individual contributions, however. Indeed, there are all too few individuals who have been peripatetic enough, or long-lived enough, to be able to reconstruct a wide perspective on the history of holography. The participants at this conference are nevertheless important sources of information. Latent within each of you is one perspective of the image representing the history of holography. A number of personal accounts have already been published ${ }^{52-56}$ and several syntheses made of current activities, particularly by the artistic community. ${ }^{57-60}$ But certain parts of that history are poorly illuminated, too, amounting to 'black holes' where individuals or firms have not stayed still long enough to record a durable perspective. For such reasons, this latent history may not be entirely uniform, and is gradually disappearing as memories fade and participants drift away.

Nor can this history be colorfully illuminated with a single source. We cannot grasp the breadth of the evolution of holography merely from its technical history, or its intellectual trail, or its economic repercussions, although each of these components is important. ${ }^{61-65}$ To reconstruct a realistic image of the history of holography requires the synthesis of many perspectives: contributions are needed from many participants. I am seeking input from as many practitioners as possible across the full spectrum of activities making up the field of holography over its first 55 years. Not just scientists and engineers, either, but artists, entrepreneurs, and enthusiasts who have made this subject their own. In effect, this audience comprises, as it were, a collective hologram, and each of you can think of yourself as an individual diffractive constituent reconstructing a particular perspective.

There are two important ways in which participants can contribute to this research. The first is by contributing to the recording of oral histories through extended interviews either in person or by telephone. These interviews will be deposited at the Neils Bohr library in Maryland, which is managed by the American Institute of Physics (AIP) and its Center for the History of Physics. There, the recordings will form part of a growing historical archive of physics available to subsequent historians. Oral histories should not involve merely the great and the good; the social history of holography has involved several distinct sub-cultures and thousands of practitioners: physicists, engineers, artists, entrepreneurs, enthusiasts, amateurs and dreamers.

Secondly, this history project involves the study of material records: file collections, archives, business records, correspondence and, of course, holograms themselves. If you have, or know of, personal, academic, institutional or corporate records that could be made available for historical research, or could contribute your time to the oral history work, I would greatly appreciate hearing from you.

As this conference clearly shows, the development of holography is ongoing, and the writing of its history is a work in progress. But we are at a crucial point in the writing of its history, because many of the original practitioners in this field are still available or active. Some, having begun in the late 1950s or 1960s early in their careers, are now reaching retirement. Unless we begin to collect and collate memories and evanescent documents, it may soon be impossible to reconstruct a rounded, colorful and realistic history. 

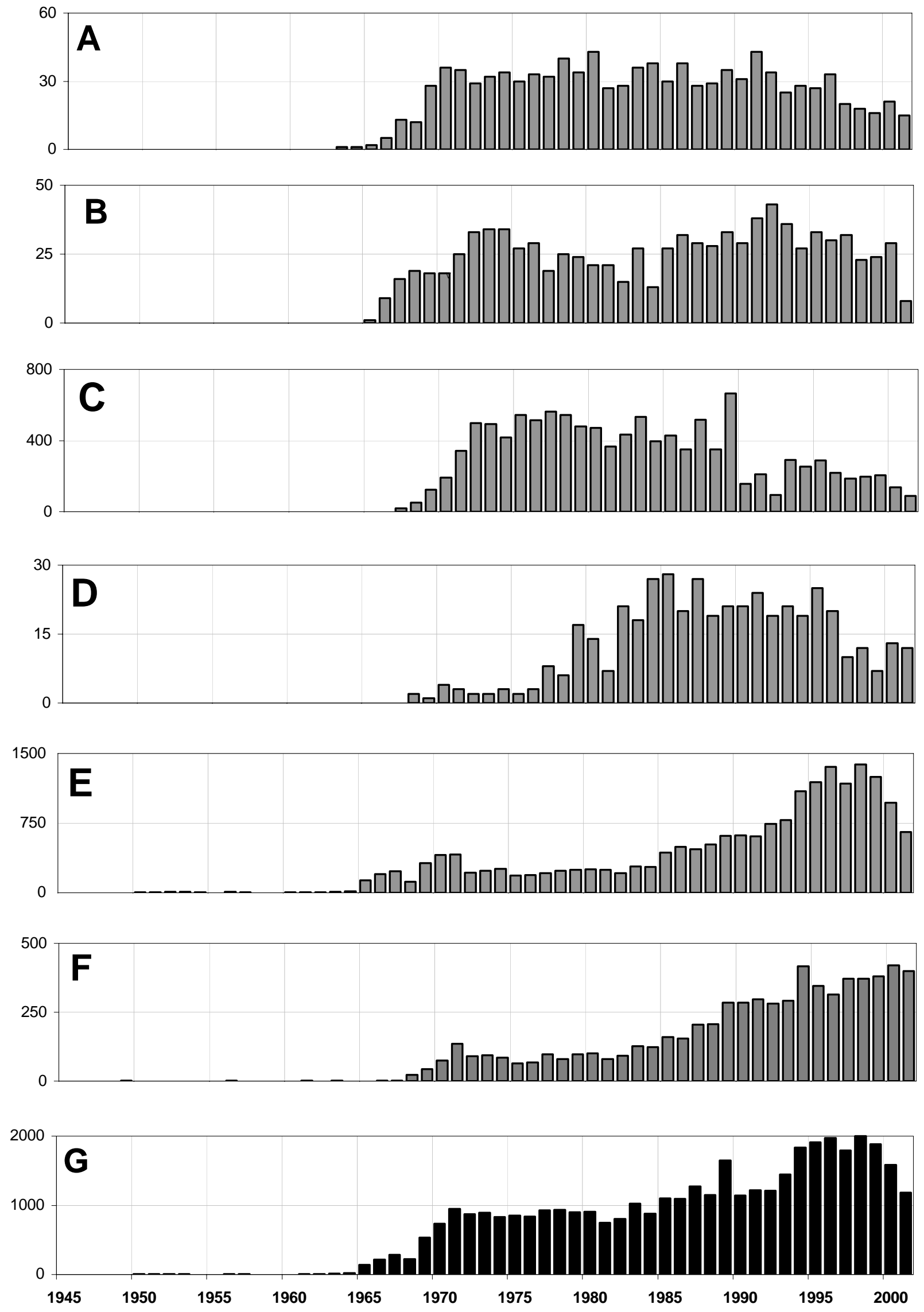
Figure 1 (previous page): Publications per year, 1945-2001 inclusive. A: Books; B: Theses; C: Conference presentations; D: Exhibitions; E: Papers; F: Patents; G: Total publications (c40,000). Sources (not exhaustive): databases including ArticlesFirst, Arts \& Humanities Citation Index, Dissertations Abstracts, INSPEC, MedLine, PsycINFO, Social Sciences Citation Index and WorldCat; European and world patents; artists' CVs; and literature reviews. ${ }^{66-68}$ These sources very likely under-represent publication activity, particularly during the early 1970s and for exhibitions. The data are also biased in that they omit publications that do not refer explicitly to holography in titles or abstracts.

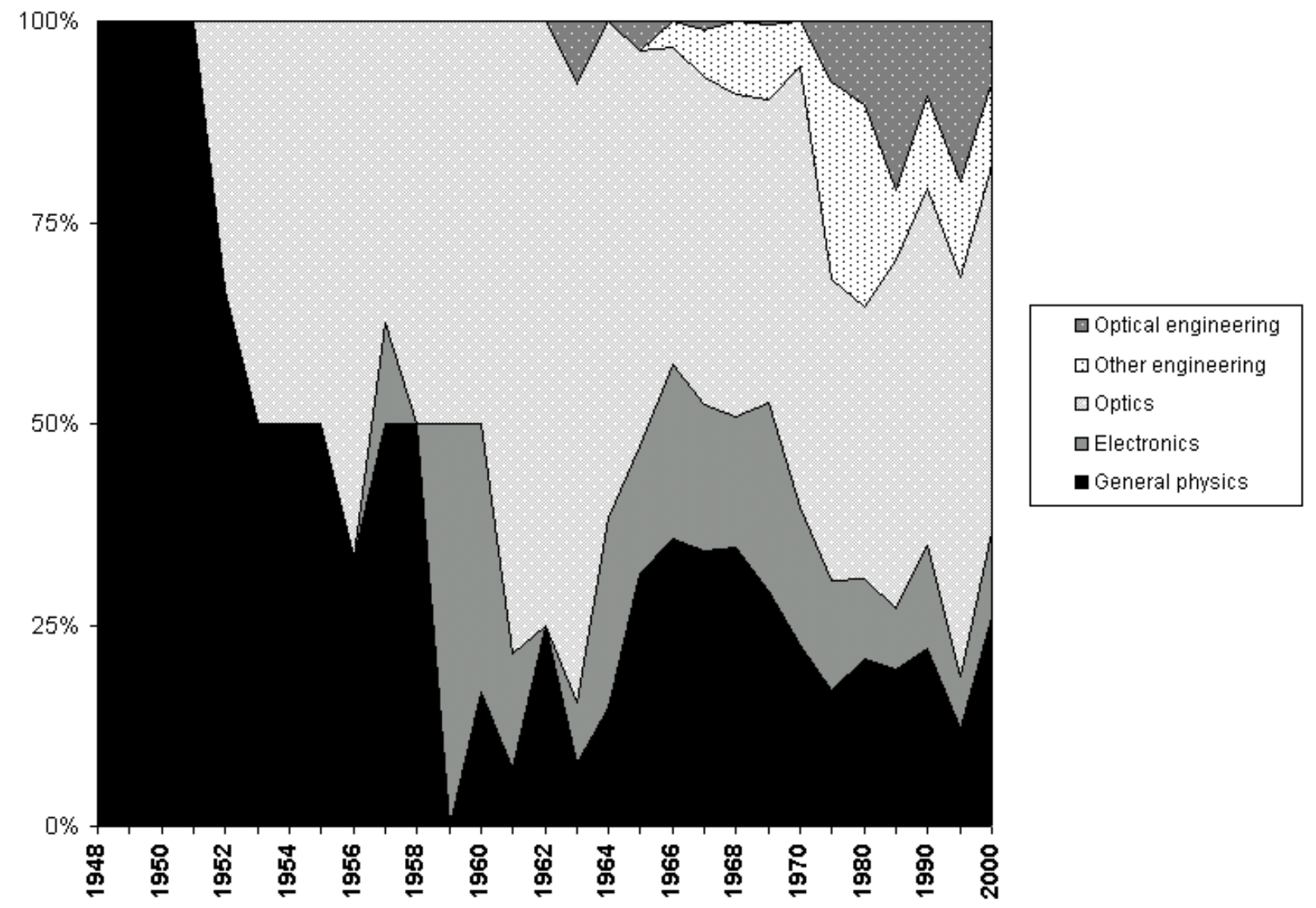

Figure 2: Distribution of papers on holography by journal type. 'Optical Engineering' includes, for example, SPIE journals and the Soviet Journal of Optical Technology; 'Other Engineering' comprises non-optical engineering journals; 'Optics' includes some two dozen publications including Optical Society of America (OSA) journals, Acta Optica Sinica, Optics Communications, Optik, Journal d'Optique, etc; 'Electronics' includes some three dozen publications such as IEEE journals and Quantum Electronics; 'General Physics' journals include, for example, Nature, Applied Physics Letters, Comptes Rendus, etc. This Figure does not include conference proceedings. Note the compressed horizontal scale after 1970. Sources of data are those listed under Figure 1.

\section{ACKNOWLEDGEMENTS}

The author acknowledges with gratitude research grants from the British Academy, the Shearwater Foundation and the Carnegie Trust for the Universities of Scotland; a grant-in-aid from the Friends of the Center for History of Physics, American Institute of Physics; and, the research assistance of Elisabeth McNair-Johnston. 


\section{REFERENCES}

1 Dennis Gabor, "Holography, 1948-1971", Science. 177 (46), 299 (1972).

2 Yu N. Denisyuk and V. Gurikov, "Advancement of Holography, Investigations by Soviet Scientists", History and Technology 8 (2), 127 (1992).

3 Emmett N. Leith, "Overview of the development of holography", The Journal of Imaging Science and Technology 41 (3), 201 (1997).

4 Joan Lisa Bromberg, The Laser in America, 1950-1970. (MIT Press, Cambridge, Mass., 1991).

Jeff Hecht, Laser Pioneers. (Academic Press, New York, 1992).

6 Charles H. Townes, How the Laser Happened: Adventures of a Scientist. (Oxford University Press, Oxford, 2002).

Dennis Gabor, "A new microscopic principle", Nature 161, 777 (1948).

8 Dennis Gabor, "Microscopy by reconstructed wavefronts I." Proceedings of the Royal Society of London, Series A 197, 454 (1949).

9 M. E. Haine and J. Dyson, "A modification to Gabor's diffraction microscope", Nature 166, 315 (1950).

10 G. L. Rogers, "Gabor diffraction microscopy: the hologram as a generalized zone-plate", Nature 166, 237 (1950).

11 Hussein M. A. El Sum and P. Kirkpatrick, "Microscopy by reconstructed wave-fronts", Physical Review 85, 763 (1952).

12 P. Kirkpatrick and H. M. A. El-Sum, "Image formation by reconstructed wavefronts", Journal of the Optical Society of America 46, 825 (1956).

13 W. L. Bragg, "Microscopy by reconstructed wavefronts", Nature 166, 399 (1950).

14 Yu N. Denisyuk, "On the reflection of optical properties of an object in the wave field of light scattered by it", Doklady Akademii Nauk SSSR 15 (5), 1275 (1962).

15 Yu N. Denisyuk and R. R. Protas, "Improved Lippmann photographic plates for the record of standing light waves (in Russian)", Optika i Spektroskopija 14, 721 (1963).

$16 \mathrm{Yu}$ N. Denisyuk, "On the problem of a photograph reproducing the full illusion of the reality of the object depicted (in Russian)", Zhurnal Nauchnoi i Prikladnoi Fotografi i Kinematografi 11, 46 (1966).

17 Yu N. Denisyuk, "The work of the State Optical Institute on holography", Soviet Journal of Optical Technology 34 (6), 706 (1967).

18 Hans Wilhelmsson, "Holography: a new scientific technique of possible use to artists", Leonardo 1 (2), 161 (1968).

19 Wiebe E. Bijker, Thomas P. Hughes, and T. J. Pinch, The Social Construction of Technological Systems: New Directions in the Sociology and History of Technology. (M.I.T. Press 1990, Cambridge, Mass., 1990).

20 John M. Staudenmaier, Technology's Storytellers: Reweaving the Human Fabric. (MIT Press, Cambridge, Mass, 1985).

21 George Basalla, The Evolution of Technology. (Cambridge University Press, Cambridge, 1988).

22 Emmett N. Leith and Juris Upatnieks, "Photography by laser", Scientific American 224, 24 (1965).

23 Emmett N. Leith and Juris Upatnieks, "Some recent results in holography". presented at the Northeast electronics research and engineering meeting, Boston, MA, 1968 (unpublished).

24 Emmett N. Leith and Juris Upatnieks, "Holography at the crossroads", Optical Spectra 4 (9), 21 (1970).

25 Emmett N. Leith and Juris Upatnieks, "Progress in holography", Physics Today 25 (3), 28 (1972).

26 Emmett N. Leith, "White-light holograms", Scientific American 235 (4), 80 (1976).

27 Emmett N. Leith, in Applications of Holography and Optical Data Processing. (Pergamon Oxford UK, 1977), pp. $\mathrm{xvi}+723$.

28 Emmett N. Leith, "Holography - the promise fulfilled", Proceedings of the SPIE 532, 2 (1985).

29 Dennis Gabor, "The outlook for holography", Optik 28 (5), 437 (1969).

30 Dennis Gabor, "Holography, past, present and future". presented at the SPIE seminar on developments in holography, 1971 (unpublished).

31 P. Greguss, "Thoughts on the future of holography in biology and medicine", Optics and Laser Technology 7 (6), 253 (1975).

32 Yu N. Denisyuk, "Holography and its prospects (review)", Journal of Applied Spectroscopy 33 (3), 901 (1980).

33 Emmett N. Leith, "Holography - Past, present and future", Proceedings of the International Symposium on Display Holography 2, 3 (1985).

34 H. J. Caulfield, Jacques E. Ludman, and Juanita Riccobono (ed.), Holography for the New Millennium (2002), New York:Springer.

35 "Symposium on Modern Optics". Polytechnic Inst. Brooklyn NY USA, 1967 (unpublished).

36 "Seminar In-Depth on Holography". San Francisco, 1968 (unpublished). 
37 "Symposium on Engineering Uses of Holography". Univ of Strathclyde, 1968 (unpublished).

38 "Applications de l'Holographie; Comptes Rendus du Symposium International d'Holographie". Besançon, France, 1970 (unpublished).

39 Emmett N. Leith, "Some highlights in the history of display holography", Proceedings of the International Symposium on Display Holography 1, 1 (1983).

40 Lloyd G. Cross and Cecil Cross, "HoloStories: Reminiscences and a prognostication on holography", Leonardo 25 (5), 421 (1992).

41 Stephen A. Benton, "Rainbow holograms", Journal of the Optical Society of America 50, 1545 (1969).

42 Umberto Eco and William Weaver, Travels in Hyper-Reality: Essays. (Picador, London, 1986).

43 David Pizzanelli, "Evolution of the mythical hologram", Proceedings of the SPIE The International Society for Optical Engineering 1732, 430 (1992).

44 Karl H. Pribram, "The neurophysiology of remembering", Scientific American 220 (1), 73 (1969).

45 D. Bohm, "Quantum theory as an indication of a new order in physics. II. Implicate and explicate order in physical law", Foundations of Physics 3 (2), 139 (1973).

46 David Bohm and John Welwood, "Issues in physics, psychology and metaphysics: A conversation", Journal of Transpersonal Psychology 12 (1), 25 (1980).

47 Ken Wilber, The Holographic Paradigm and Other Paradoxes: Exploring the Leading Edge of Science. (Shambhala, Boulder ; London, 1982).

48 Karl Pribram, H., "Rethinking Neural networks: Quantum Fields and Biological Data". presented at the First Appalachian Conference on Behavioral Neurodynamics., Hillsdale, New Jersey., 1993 (unpublished).

49 Nicholas J. Phillips, personal communication, De Montfort University, 18 Sep 2002.

50 L. Speer, "Before Holography - a Call for Visual Literacy", Leonardo 22 (3-4), 299 (1989).

51 Edward Earle, Points of View: The Stereograph in America -- A Cultural History. (Visual Studies Workshop Press, Rochester, NY, 1979).

52 S. S. Shushurin, "On the history of holography", Soviet-Physics - Uspekhi 14 (5), 655 (1972).

53 Matt Lehmann, "Holography's early days at Stanford University", Holosphere 11 (9), 1 (1982).

54 Nancy Gorglione, "Forms of light: a personal history in holography", Leonardo 25 (5), 473 (1992).

55 Dan Schweitzer, "Interference: a holographer's personal history", Leonardo 25 (5), 459 (1992).

56 Richard D. Rallison, "The history of dichromates", 2001, http://www.xmission.com/ ralcon/dichrohist.html

57 Peter Zec, Holographie : Geschichte, Technik, Kunst. (DuMont, Köln, 1987).

58 Al Razutis, Victor Ralys, and Sally Weber, "West-coast artists in light" (1998), Los Angeles, Calif.: Visual Alchemy, videorecording

59 Sarah Radley Maline, Art Holography, 1968-1993: A Theatre of the Absurd, PhD, University of Texas at Austin, 1995.

60 Georges Dyens, (CD-ROM) Art Holography - The Real Virtual 3D Images (Université de Québec à Montréal, Montreal, 2001).

61 F. Iwata, "History of holography display in Japan", Proceedings of the SPIE 747, 116 (1987).

62 Stephen A. Benton, "Ten years of white-light holography". presented at the Electro-optics/Laser International 1980, London, UK, 1980 (unpublished).

63 G. M. Brown, "From tire testing to holometry and beyond", Proceedings of the SPIE The International Society for Optical Engineering 2004, 2 (1994).

64 J. M. Lerner, "Ruled and holographic gratings: a historical perspective", Proceedings of the SPIE The International Society for Optical Engineering 2532, 2 (1995).

65 K. A. Stetson, "The problems of holographic interferometry", Experimental Mechanics 39 (4), 249 (1999).

66 Thomas Kallard, Holography: State of the Art Review 1969. (Optosonic Press, New York, 1969).

67 Thomas Kallard, Holography: State of the Art Review 1970. (Optosonic Press, New York, 1970).

68 Thomas Kallard, Holography: State of the Art Review 1971-1972. (Optosonic Press, New York, 1972). 